\title{
Article
}

\section{The Potential of Cylindrical Piezoelectric Transducers for High-Frequency Acoustic Energy Harvesting}

\author{
Shehab Salem ${ }^{1, *}$, Karel Fraňa ${ }^{1}$ [D and Iva Nová ${ }^{2}$ \\ 1 Department of Power Engineering Equipment, Faculty of Mechanical Engineering, Technical University of \\ Liberec, 46117 Liberec, Czech Republic; karel.frana@tul.cz \\ 2 Department of Technology, Faculty of Mechanical Engineering, Technical University of Liberec, \\ 46117 Liberec, Czech Republic; iva.nova@tul.cz \\ * Correspondence: shehab.ashraf.salem@tul.cz
}

Citation: Salem, S.; Fraňa, K.; Nová, I. The Potential of Cylindrical Piezoelectric Transducers for High-Frequency Acoustic Energy Harvesting. Energies 2021, 14, 5845. https://doi.org/10.3390/en14185845

Academic Editor: Francesc Pozo

Received: 25 July 2021

Accepted: 12 September 2021

Published: 15 September 2021

Publisher's Note: MDPI stays neutral with regard to jurisdictional claims in published maps and institutional affiliations.

Copyright: (c) 2021 by the authors. Licensee MDPI, Basel, Switzerland. This article is an open access article distributed under the terms and conditions of the Creative Commons Attribution (CC BY) license (https:// creativecommons.org/licenses/by/ $4.0 /)$.

\begin{abstract}
The work presented in this paper studies the potential of cylindrical piezoelectric transducers for harvesting high-frequency acoustic energy. The cylinder was made of a modified PZT (lead zirconate titanate) and had the shape of a squared cylinder with a side length of $4 \mathrm{~cm}$ and a wall thickness of $1 \mathrm{~mm}$. The study used open-circuit measurements to study the relationship between the sound wavelength and the cylinder size and its effect on the performance of energy harvesting. The cylinder was found to give the best performance at a frequency of $20 \mathrm{kHz}$. In addition to open-circuit measurements, closed-circuit measurements were performed to demonstrate the ability to dissipate energy harvested from $20 \mathrm{kHz}$ sound waves across an electric load. The load was designed in a series of experimental steps that aimed at optimizing an impedance-matched energy harvester. Finally, the cylinder was tested at the optimized load conditions, and it was possible to harvest and store energy with a power of $67.6 \mu \mathrm{W}$ and harvesting efficiency of $86.1 \%$.
\end{abstract}

Keywords: smart materials; piezoelectric; energy harvesting; high frequency; acoustic energy; cylinders

\section{Introduction}

Currently, the environment is facing critical challenges that threaten numerous life forms on the planet. These challenges come as a result of the energy-related activities adopted by mankind over the last few decades. Therefore, there has been a growing effort to push energy systems towards sustainability and clean energy sources. Among the forms of this effort is the development of energy harvesters. Energy harvesters are devices that can absorb the energy wasted in the surroundings and change it to more useful forms [1,2]. These harvesters may rely—among other types of materials—on piezoelectric materials to change the captured energy from one form to another.

Piezoelectric materials are materials that can develop electric charges on their surfaces in response to applied mechanical pressure [3,4]. Hence, it has acquired its name "piezoelectric" from the Greek language, where the word "piezo" means to push [5]. Piezoelectric materials were discovered in 1880 by the brothers Curie in naturally existing materials [6,7].

The ability of piezoelectric materials to interchange electric and mechanical energy is a result of its material structure that allows the motion of electrons upon being pressed. When this structure is subjected to mechanical pressure, electrons will be displaced, creating polarization between the negatively charged electron cloud and the positively charged nucleus. This polarization eventually forms an electric field [8,9]. It is necessary to mention that the direction of the applied pressure relative to the material structure is significant. Therefore, piezoelectric materials may be used in two modes: mode 33 and mode 31 . As shown in Figure 1a, mode 33 is the mode when the applied pressure is parallel to the material poling direction, while mode 31 is the mode when the pressure is applied perpendicular to the poling direction as shown in Figure $1 b$ [10]. 


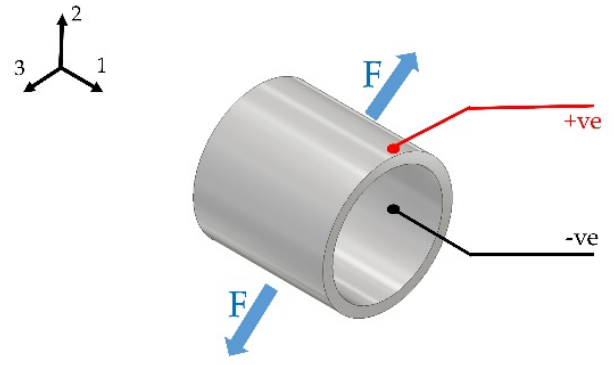

(a)
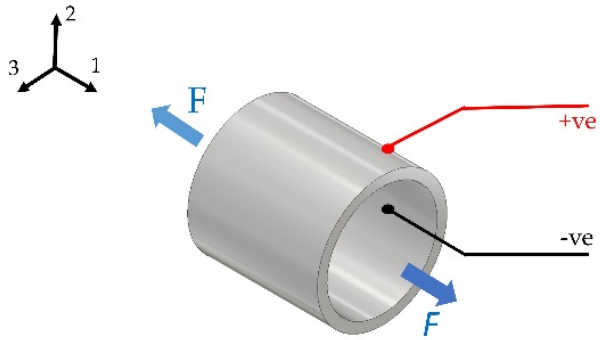

(b)

Figure 1. Piezoelectric materials may operate in two different modes depending on the direction of the mechanical force relative to the direction of material poling: (a) piezoelectric material operating in mode 33, where the mechanical force is applied parallel to the material poling direction; (b) piezoelectric material operating in mode 31 , where the mechanical force is applied perpendicular to the material poling direction.

Hassan et al. [11] compared different transduction technologies based on energy density - as energy converted per unit volume of the transducer-showing that piezoelectric transduction is the technology with the highest efficiency and the smallest size. Such facts make piezoelectric materials a favorable option during the process of designing energy harvesters where they have been used in several applications of energy harvesting. For example, research has been conducted on the use of piezoelectric transducers to harvest the energy of flow-induced vibrations. These vibrations are induced by putting a cylinder-a non-piezoelectric one-across the flow of a fluid. Being interrupted by the cylinder, the flow moves around the cylinder, inducing a wake region from which a vortex train is shed [12]. Gao at al. [13] developed a harvester of flow energy based on a piezoelectric cantilever with a cylindrical extension. The harvester managed to continuously operate an electronic thermometer chip MCP9700 using an airflow of velocity of $5.2 \mathrm{~m} / \mathrm{s}$. In addition to harvesting flow energy, piezoelectric materials have been used to harvest acoustic energy. Examples of piezoelectric energy harvesters shall be presented later in Section 4.2.

To assess the quality by which an energy harvester can harvest vibration energy, it is necessary to define a qualitative measure that would describe such a process. Mostly, researchers tend to use efficiency $\eta$, which is the ratio of the harvested electric energy to the supplied mechanical vibration energy. This number stands as the resultant final efficiency of the overall harvester taking into account all the factors governing its performance such as the electromechanical coupling factor of the material, the geometry of the transducer, the inhibited mechanical damping in the system, and the electrical damping characteristics of the load as well as of the whole circuit. Despite how simple the definition of efficiency is, it is quite challenging to agree on a strict way to evaluate efficiency because of the practical constraints on measuring the input energy. Therefore, large discrepancies can be found in the value of efficiency reported in the literature, where it can be estimated to be as high as $80 \%$ by some researchers, while others claim that it can never be more than $50 \%$.

Yang et al. [14] presented an overview of work conducted studying the efficiency by which piezoelectric energy harvesters convert energy. They reported that PZT (lead zirconate titanate)-based energy harvesters harvesting vibrational energy had the highest theoretical efficiency in the range of $50-90 \%$. Richards et al. [15] derived a formula to calculate the efficiency in the case of a system operating at the resonance frequency with impedance matched to the load's. They considered systems of low damping and high mechanical coupling. Their theoretical study predicted that efficiency may be higher than $90 \%$. However, high values of coupling are rarely achieved experimentally to justify this result. Shu et al. [16] also devised a formula for the calculation of efficiency that was based on the material coupling coefficient, mechanical damping, and normalized values of each of the harvested sound frequency as well as the electric resistance. A maximum efficiency of $46 \%$ was reported for harvesters of weak coupling, while a maximum efficiency of more than $80 \%$ was reported for harvesters of strong coupling. 
Liao et al. [17] have proposed a different way to assess the performance of piezoelectric energy harvesters, where they derive a new efficiency that is analogous to the material loss factor. This efficiency is calculated as the ratio between the strain energy over each cycle and the power output. They validated this new quantity by numerical simulations, and it was estimated that harvesters would have a maximum efficiency of $2.5 \%$ around the resonance frequency.

Yuan et al. [18] also compared various designs of acoustic energy harvesters reported in the literature. They did not base their comparison on the efficiency of energy conversion of these harvesters; however, they derived their own parameter and called it "Metric". Their parameter is set to give a higher score for a smaller harvester that is able to harvest more power at a lower input sound power. Therefore, they devised their Metric according to Equation (1), where it is set to be the ratio between the harvested power and the product of the harvester volume and the square of the involved sound pressure, where P, Vol, and Pre are the harvested power in $\mu \mathrm{W}$, the harvester volume in $\mathrm{cm}^{3}$, and the involved sound pressure in Pascals, respectively. Their motivation behind using a squared value of sound pressure is that sound intensity is proportional to the square of sound pressure as shown in Equation (2) which relates sound intensity I to the sound pressure Pre via the acoustic impedance $Z_{\text {acoustic }}$.

$$
\begin{gathered}
\text { Metric }=\frac{\mathrm{P}}{\mathrm{Vol}^{*} \text { Pre }^{2}} \\
\mathrm{I}=\frac{\text { Pre }^{2}}{\mathrm{Z}_{\text {acoustic }}}
\end{gathered}
$$

Using their parameter (i.e., Metric), the authors rated seventeen different designs of acoustic energy harvesters from the literature. The harvesters' operating conditionssound frequency and pressure-spanned over a wide range. The list included harvesters operating at a sound frequency in the range of $146-13,570 \mathrm{~Hz}$, with most of the list targeting frequencies under $1 \mathrm{kHz}$. On the other hand, the operating sound pressure ranged over 1-563.7 Pa which corresponds to an SPL (sound pressure level) of 94-149 dB. Sixteen designs out of the presented seventeen achieved a value of Metric in the range of $7.7228 *$ $10^{-12}-0.1885 \mu \mathrm{W} /\left(\mathrm{cm}^{3} \cdot \mathrm{Pa}^{2}\right)$, while one last design achieved $14.536 \mu \mathrm{W} /\left(\mathrm{cm}^{3} \cdot \mathrm{Pa}^{2}\right)$.

The goal of this work was to study the potential of cylindrical piezoelectric transducers for the application of high-frequency acoustic energy harvesting. Piezoelectric transducers have already been used in many shapes such as circular disks, plates, annular disks, and bending elements. Considering planar harvesters, such as plate-based and ring-based designs, the harvester's dimension that is in the direction of acoustic wave propagation is the transducer thickness. Since this thickness is much smaller than the wavelength of the acoustic wave, the waves apply almost equal pressure on the two sides of the transducer which may reduce the transducer output [19]. However, a cylindrical geometry might have its advantages over planar geometries due to the bigger dimension-diameter as opposed to thickness in planar geometries - in the direction of the acoustic wave propagation. Moreover, this work targets noise in the high-frequency range up to $20 \mathrm{kHz}$. According to a study presented by Fletcher at al. [20], it was found that noises with a sound pressure level of $100 \mathrm{~dB}$ and a frequency near $20 \mathrm{kHz}$ often exist in public places. Interestingly, a hand drier can produce a noise with an SPL of $84 \mathrm{~dB}$ at $40 \mathrm{kHz}$.

The cylinder under study was made of PZT which is a suitable material for the application of energy harvesting thanks to its high piezoelectric constant [21]. The electrical impedance of the cylinder was already studied over a wide frequency spectrum in [22], and it was found that the cylinder impedance tended to drop as the frequency increased, and this drop happened almost exponentially in the acoustic spectrum. Moreover, it was found that the cylinder has a capacitive nature. The work in this paper can be divided into two parts. The first part studied the effect of sound frequency and, hence, the sound wavelength on the energy harvesting process. Then, the second part demonstrates the 
operation of the cylinder in a complete energy harvester, harvesting sound waves with a frequency of $20 \mathrm{kHz}$.

\section{Materials and Methods}

\subsection{Materials}

The used piezoelectric transducer was made of PZT-5A, which is a modified lead zirconate titanate. According to the manufacturer, the material had piezo constants as shown in Table 1, where it had a piezoelectric voltage constant of $-11.5 \mathrm{mV} . \mathrm{m} / \mathrm{N}$ and $22 \mathrm{mV} . \mathrm{m} / \mathrm{N}$ in the 31 and 33 directions, respectively. It also had resonance frequency constants in the radial as well as the thickness modes which were $1950 \mathrm{~Hz} . \mathrm{m}$. Moreover, the cylinder had a square shape with a diameter, $D_{\text {cyl }}$, of $40 \mathrm{~mm}$ and a wall thickness, $t$, of $1 \mathrm{~mm}$ as summarized $\mathrm{n}$ Table 2.

Table 1. Electromechanical and acoustic-mechanical properties of the used piezoelectric cylinder.

\begin{tabular}{cc}
\hline Quantity & Value \\
\hline $\begin{array}{c}\text { Piezoelectric voltage } \\
\text { Constants }\left[10^{-3} \frac{\mathrm{Vm}}{\mathrm{N}}\right]\end{array}$ & $\mathrm{g}_{33}=22$ \\
$\mathrm{~g}_{31}=-11.5$ \\
\hline Piezoelectric charge & \\
Constants $\left[10^{-12} \frac{\mathrm{C}}{\mathrm{N}}\right]$ & $\mathrm{d}_{33}=500$ \\
\hline Frequency constants (Hz.m) & $\mathrm{N}_{\mathrm{p}}=1950$ \\
$\mathrm{~N}_{\mathrm{t}}=1950$ \\
\hline Mechanical quality factor $(-)$ & 100 \\
\hline
\end{tabular}

Table 2. Dimensions of the piezoelectric cylinder.

\begin{tabular}{ccc}
\hline $\begin{array}{c}\text { Length } \\
(\mathbf{m m})\end{array}$ & $\begin{array}{c}\text { Outer Diameter, } \mathbf{D}_{\text {cyl }} \\
(\mathbf{m m})\end{array}$ & $\begin{array}{c}\text { Wall Thickness, } \mathbf{t} \\
(\mathbf{m m})\end{array}$ \\
\hline 40 & 40 & 1 \\
\hline
\end{tabular}

Using these data, it was possible to calculate the resonance frequency of the various vibration modes of the cylinder. For the setup used in this paper, the vibration modes that were of interest were the radial and the thickness modes with the resonance frequencies defined as $F_{r_{p}}$ and $F_{r_{t}}$, respectively. Using Equations (3) and (4), it was possible to calculate $\mathrm{F}_{\mathrm{r}_{\mathrm{p}}}$ and $\mathrm{F}_{\mathrm{r}_{\mathrm{t}}}$ to be $48.75 \mathrm{kHz}$ and $1950 \mathrm{kHz}$, respectively, as summarized in Table 3.

$$
\begin{gathered}
\mathrm{F}_{\mathrm{r}_{\mathrm{t}}}=\mathrm{N}_{\mathrm{t}} / \mathrm{t} \\
\mathrm{F}_{\mathrm{r}_{\mathrm{p}}}=\mathrm{N}_{\mathrm{p}} / \mathrm{D}_{\mathrm{cyl}}
\end{gathered}
$$

Table 3. Resonance frequencies of the piezoelectric cylinder.

\begin{tabular}{cc}
\hline $\begin{array}{c}\mathbf{F}_{\mathbf{r}_{\mathbf{p}}} \\
(\mathbf{k H z})\end{array}$ & $\begin{array}{c}\mathbf{F}_{\mathbf{r}_{\mathbf{t}}} \\
(\mathbf{k H z})\end{array}$ \\
\hline 48.75 & 1950 \\
\hline
\end{tabular}

\subsection{Description of the Experimental Setup}

As shown in Figure 2, the experimental setup was built such that it was composed of speakers (1) supplying acoustic waves of controlled frequency onto the cylinder (2). To do so, aluminum profiles were assembled to form a crane (3) from which the cylinder could be hanged. The cylinder was hanged from the crane using a malleable metallic strap (4) covered with a plastic cover (5). The cover was intended to have two functions: the first function was to electrically insulate the cylinder from the conductive aluminum frame, 
while the second function was to protect the cylinder's surface from scratches that may develop from metal-to-metal contact with the strap. Such a measure was necessary as such cracks may degrade the piezoelectric material.

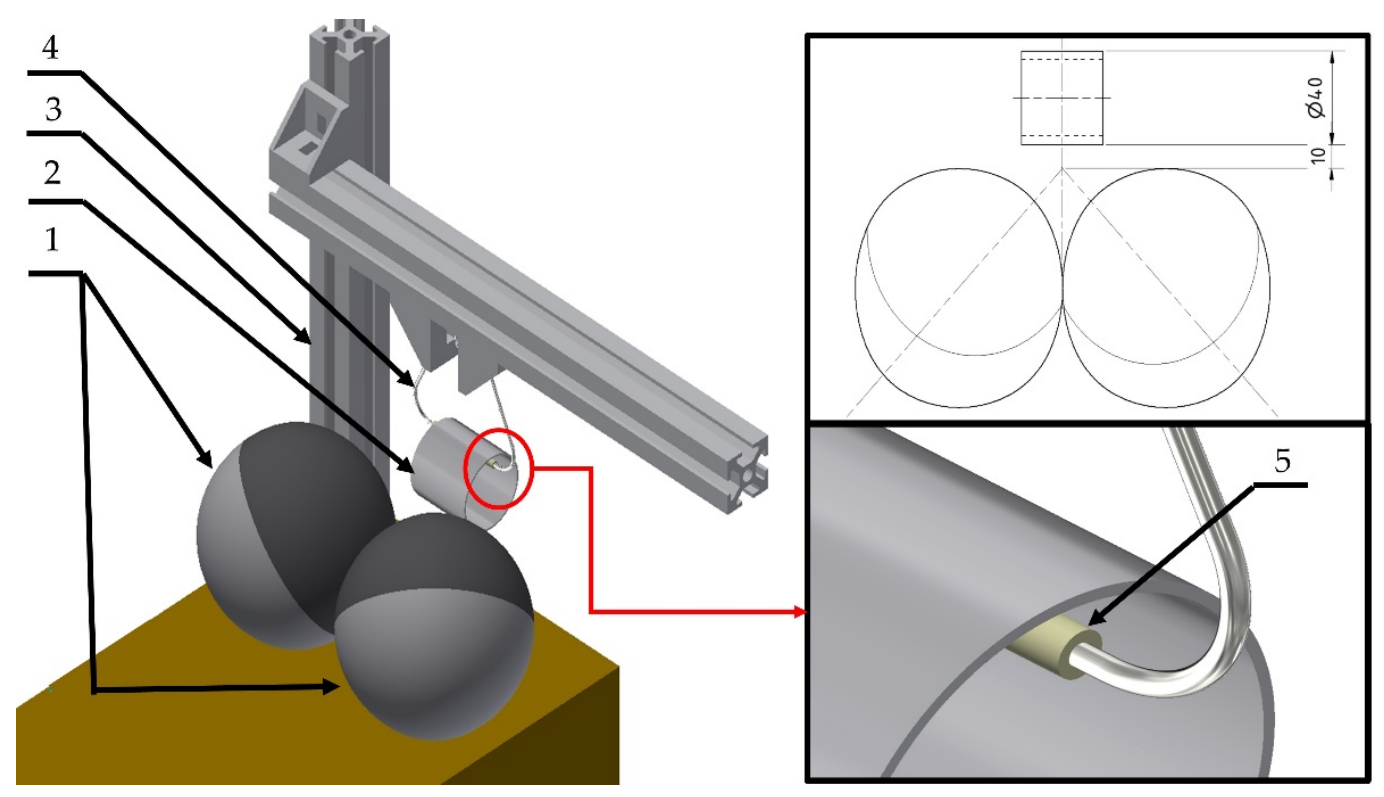

Figure 2. The setup of the experiment was constructed such that the speakers (1) supplied sound waves of controlled frequency onto the piezoelectric cylinder (2). The cylinder (2) was supported from a crane (3) using a metallic strap (4) that was insulated with a plastic cover (5). The cylinder had a diameter of $40 \mathrm{~mm}$ and was placed $10 \mathrm{~mm}$ away from the speakers-all dimensions are expressed in $\mathrm{mm}$.

After supporting the cylinder from the frame, the speakers were placed such that sound waves would be applied radially onto the cylinder. The main consideration behind the design of this setup was to support the cylinder from one point to avoid damping the vibration of the cylinder. Moreover, the design aimed to minimize the effect of sound reflection. This was achieved by minimizing the number of objects-including the groundthat were in the vicinity of the speakers.

The cylinder was connected to a breadboard by a pair of electric wires that were soldered to the inner and outer surfaces of the cylinder. Into the breadboard, four Schottky diodes BAT 48 were mounted forming a full-wave rectifier as shown in Figure 3, where the cylinder was modeled as an AC source. The BAT 48 diodes were produced by STMicroelectronics and were specifically preferred due to the fact of their relatively low forward voltage value, $V_{f}$, where it had a $V_{f}$ of $240 \mathrm{mV}$. Hence, it was determined that a total voltage drop of $480 \mathrm{mV}$ should be imposed on the output of this circuit.

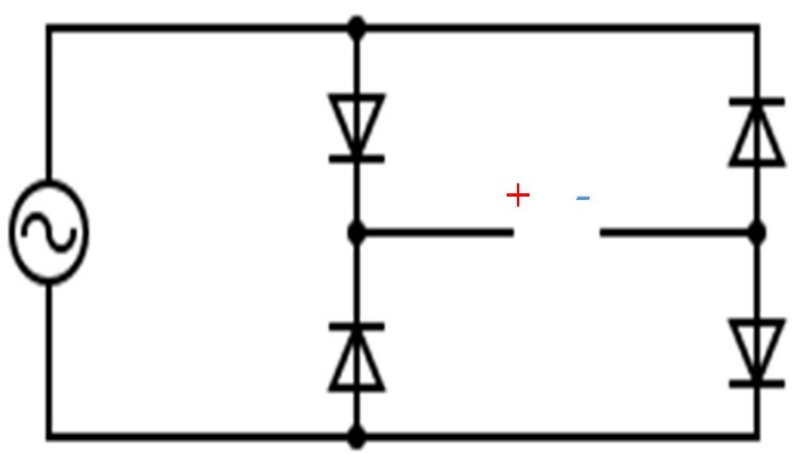

Figure 3. A schematic representation of the source circuit, formed by an AC source connected to a full-wave rectifier. 


\subsection{Methods}

The investigation was conducted in two phases. In Phase (1), the effect of sound frequency on the energy harvesting performance was studied. In this phase, the cylinder underwent measurements - defined as Case (0) —at different sound frequencies aimed at defining the optimum frequency for energy harvesting. Then, Phase (2) sought to demonstrate the ability to use the cylinder as a transducer in an acoustic energy harvester. The design of the harvester targeted impedance matching at the optimum frequency found in Phase (1). The harvester was designed experimentally in two steps, defined later to be Case (1) and Case (2). For a better understanding of the process, Figure 4 summarizes the procedure followed in the two phases, where $\mathrm{f}, \mathrm{L}$, and $\mathrm{C}$ are the sound frequency, the circuit inductance, and the circuit capacitance, respectively, while $\mathrm{P}_{\text {electric }}$ and $\mathrm{P}_{\text {acoustic }}$ are the involved electric and acoustic powers, respectively.

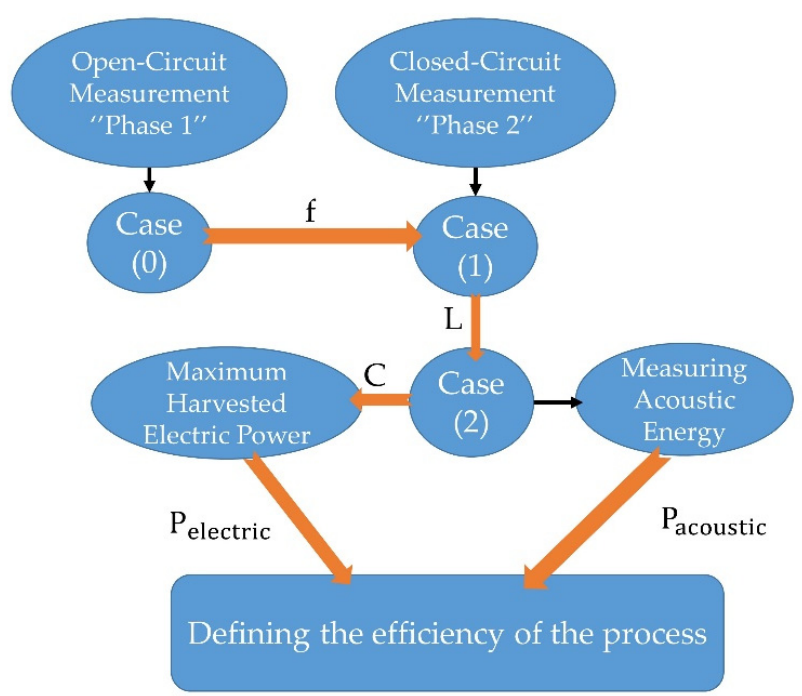

Figure 4. An overview of the measurements performed on the cylinder.

\subsubsection{Phase (1)}

In Phase (1), the cylinder was subjected to sound waves of different frequencies while the generated voltage over the bridge poles was monitored. The experiment was set-up as defined above such that the distance between the speakers and the cylinder was almost $1 \mathrm{~cm}$. A frequency sweep was performed from a frequency of $20 \mathrm{kHz}$, in steps of $1 \mathrm{kHz}$, up to a frequency of $1 \mathrm{kHz}$. Then, a step of $200 \mathrm{~Hz}$ was used from $1000 \mathrm{~Hz}$ up to $200 \mathrm{~Hz}$. In case a peak point was found, additional measurements were performed in a range of $1 \mathrm{kHz}$ centered at the found peak with a step between measurements of $200 \mathrm{~Hz}$. At each frequency, the generated voltage across the circuit was measured using an oscilloscope UT-81A as shown in Figure 5.

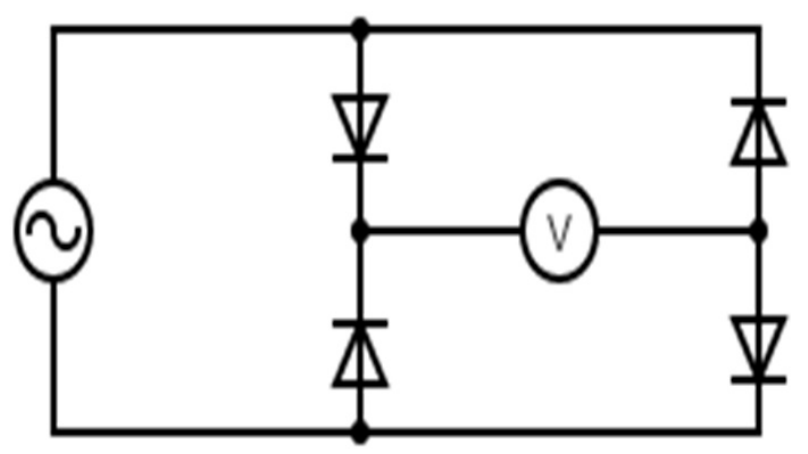

Figure 5. A schematic diagram of the circuit used in the open-circuit measurements, where the output voltage of the rectifier was measured via an oscilloscope. 
The significance of Phase (1) was that it helped define an optimum frequency for maximized energy harvesting for this specific cylinder. It will be shown later in Section 3 (Results) that this frequency was found to be $20 \mathrm{kHz}$.

\subsubsection{Phase (2)}

In Phase (2), an energy harvester was constructed respecting the maximum power transfer theorem. According to this theorem, a power source will transfer to its load maximum amount of power when the source and the load are of conjugated impedances, i.e., matched impedance [16]. The harvester was optimized for sound waves with a frequency of $20 \mathrm{kHz}$, which were found to provide the best performance in Phase 1 . Knowing that the cylinder impedance at a frequency of $20 \mathrm{kHz}$ is $1.93-50.7 \mathrm{j} \Omega$ [22], the load can be designed using Equations (5)-(7) to have an electric impedance of $1.93+50.7 \mathrm{j} \Omega$, where $Z_{t}, R, Z_{l}$ and $Z_{c}$ refer to the total series impedance, the resistor, the impedance of an inductor, and a capacitor, respectively, while $\mathrm{f}, \mathrm{L}$, and $\mathrm{C}$ refer to the signal frequency, the inductance of the inductor, and the capacitance of the capacitor, respectively. Therefore, the load will use a resistor of value $2 \Omega$. However, it will be challenging to define the inductance and the capacitance since their impedance depends mainly on the frequency of the signal flowing in the load.

$$
\begin{gathered}
Z_{t}=R+\left(Z_{l}-Z_{c}\right) j \\
Z_{l}=2 \Pi f L, \\
Z_{c}=\frac{1}{2 \Pi f C}
\end{gathered}
$$

Since the output signal of the source circuit has been through a full-wave rectifier bridge; therefore, the signal is expected to be ideally of a frequency that is double the sound frequency. However, it was clear from the patterns obtained from the oscilloscope during the open-circuit experiment that the rectification did not occur with $100 \%$ efficiency. So, it was not clear which frequency to consider: 20 or $40 \mathrm{kHz}$.

To solve this question, the problem was divided into two steps: Case (1) and Case (2). In the first step, two designs of the load were considered. The load in each case was composed of the $2 \Omega$ resistor, an inductor, and a capacitor. Design (1A) was to achieve impedance matching considering a sound frequency of $20 \mathrm{kHz}$, while Design (1B) considered a frequency of $40 \mathrm{kHz}$.

Since the influence of an inductor on the total value of impedance was more than the capacitor's, according to Equations (5)-(7), it was decided to vary the inductance value while keeping the capacitance constant at a value of $220 \mu \mathrm{F}$. Hence, it was possible to choose an inductance value of $440 \mu \mathrm{H}$ for Case (1A) and $220 \mu \mathrm{H}$ for Case (1B) using Equations (5)-(7). Table 4 summarizes the details of the two circuits, while Figure 6 shows the schematic diagrams for Cases (1A) and (1B).

Table 4. Summary of the electric impedance applied in the different circuits of Case (1).

\begin{tabular}{cccc}
\hline Circuit & Flowing Signal Frequency $\mathbf{( k H z )}$ & Used Inductor $(\mu \mathbf{H})$ & \multicolumn{2}{c}{ Total Impedance $(\Omega)$} \\
\hline Source Circuit & 20 & - & $1.93-50.7 \mathrm{j}$ \\
\hline Load Circuit Case (1A) & 20 & 440 & $2+55.246 \mathrm{j}$ \\
\hline Load Circuit Case (1B) & 40 & 220 & $2+55.23 \mathrm{j}$ \\
\hline
\end{tabular}

After assembling the electric circuit for each case, sound waves with a frequency of $20 \mathrm{kHz}$ were applied onto the cylinder using the same settings discussed in the open-circuit measurement. The measured parameter, however, was the overall voltage, $\mathrm{V}$, generated across the load-the R-L-C branch. The measurement was performed until the measured voltage flattened over time. It will be seen later, in Section 3 (Results), that Case (1A) achieved better results. Therefore, the inductance of $440 \mu \mathrm{H}$ was used in the next step considering the frequency to be $20 \mathrm{kHz}$. 


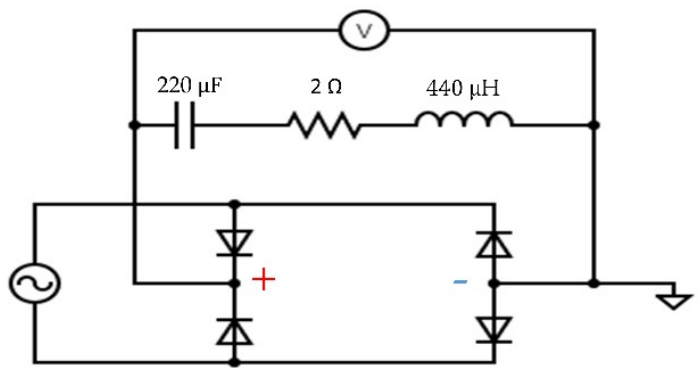

(a)

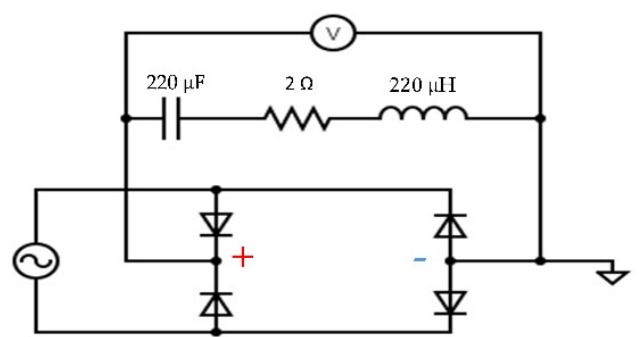

(b)

Figure 6. The schematic diagram of the electric circuit used for measurements in Case (1): (a) Case (1A) achieves balancing using a $440 \mu \mathrm{H}$ inductor assuming the frequency to be $20 \mathrm{kHz}$; (b) Case (1B) achieves balancing using a $220 \mu \mathrm{H}$ inductor assuming the frequency to be $40 \mathrm{kHz}$.

Then, in the next step, which was defined as Case (2), the capacitor value was varied while fixing the inductance value. This was performed to show the effect of achieving impedance matching on harvesting performance. Three different values of capacitance-2, 10 , and $1 \mu \mathrm{F}$-were chosen using Equations (5)-(7) to achieve balanced impedance across the whole circuit. The data of the impedance values are summarized in Table 5.

Table 5. Summary of electrical impedance of the load circuits used in Case (2).

\begin{tabular}{ccc}
\hline Used Load Capacitor $(\boldsymbol{\mu} \mathbf{F})$ & Load Impedance $(\boldsymbol{\Omega})$ & Impedance Magnitude Ratio of the Source to the Load $(-)$ \\
\hline 2 & $2+51.3 \mathbf{j}$ & 0.988 \\
\hline 10 & $2+54.49 \mathrm{j}$ & 0.933 \\
\hline 1 & $2+47.37 \mathrm{j}$ & 1.071 \\
\hline
\end{tabular}

After constructing the circuit, the experiment was conducted using the same procedure that was followed in Case (1), where sound waves with a frequency of $20 \mathrm{kHz}$ were applied to the cylinder. However, there were two practical aspects that were considered in all of the measurements involved in the two phases:

1. Taking into consideration the capacitive nature of the cylinder, it was believed that the harvesting behavior of the transducer would depend on how many charges were already stored in the cylinder. To neutralize this effect, it was set that the measurement would be repeated three times. Before each measurement, the bridge terminals were connected to a short circuit using a $2 \Omega$ resistor to dissipate any residual electric charges that might be stored in the cylinder;

2. All measurements were performed across the output terminals of the full-wave rectifier. This means that it would take into account the losses in voltage caused by the bridge. To quantify these losses and also to make sure that none of the diodes had burned out during a previous measurement, the total forward voltage across the bridge terminals was always measured before each measurement using a voltmeter set to the diode measurement mode. It was found out that the bridge imposed a total drop in voltage of 0.432 Volts.

\subsubsection{Defining the Acoustic Energy Used in Case (2)}

Two acoustic measurements were performed. The first measurement aimed at measuring the variation in the sound pressure across the distance from the speaker. The goal behind this step was to identify a position at which the sound pressure would be maximized to amplify the generated voltage and, hence, facilitate its measurement.

Then, in the second measurement, the acoustic power was measured using a microphone. Using this measurement, it would be possible to calculate the efficiency of the harvesting process. However, there were practical complications regarding the measure- 
ment of sound power level, $\mathrm{L}_{\mathrm{w}}$, or sound intensity level, $\mathrm{L}_{\mathrm{i}}$, at such a high frequency. To overcome this problem, we focused on the near field sound, since the numerical value of the sound pressure level was equal to that of the intensity level, $\mathrm{L}_{\mathrm{i}}$, to that of the velocity level, $\mathrm{L}_{\mathrm{v}}$. Hence, by measuring the sound pressure level in the near field, it would be possible to quantify the intensity, I, using Equation (8) and, hence, the total amount of power falling on the cylinder using Equation (9). In Equation (8), $\mathrm{I}_{\text {ref }}$ is taken to be $10^{-12} \mathrm{~W} / \mathrm{m}^{2}$ according to the sound intensity threshold required for human hearing, while in Equation (9), $\mathrm{D}_{\text {cyl }}$ and $\mathrm{L}_{\text {cyl }}$ were taken to be $0.04 \mathrm{~m}$.

$$
\begin{gathered}
\mathrm{I}=10^{\left(\mathrm{L}_{\mathrm{i}} / 10\right)} * \mathrm{I}_{\text {ref }}\left[\frac{\mathrm{W}}{\mathrm{m}^{2}}\right] \\
\mathrm{P}_{\text {acoustic }}=\mathrm{I} * \mathrm{~A}_{\text {cyl }}=\mathrm{I} * \pi \mathrm{D}_{\text {cyl }} \mathrm{L}_{\text {cyl }}=\mathrm{I} * 0.005[\mathrm{~W}]
\end{gathered}
$$

\section{Results}

\subsection{Case (0)}

Figure 7 shows the raw data of the measured voltage across the harvester. It can be noticed that the voltage tended to generally increase with the increase in the sound frequency, achieving a maximum voltage of $110 \mathrm{mV}$ at the ceiling of the acoustic spectrum. However, it can be noticed that a peak voltage formed at a frequency of $12.2 \mathrm{kHz}$ despite the absence of a similar peak in the cylinder impedance at such a value of frequency.

Variation of the open-circuit voltage with sound Frequency

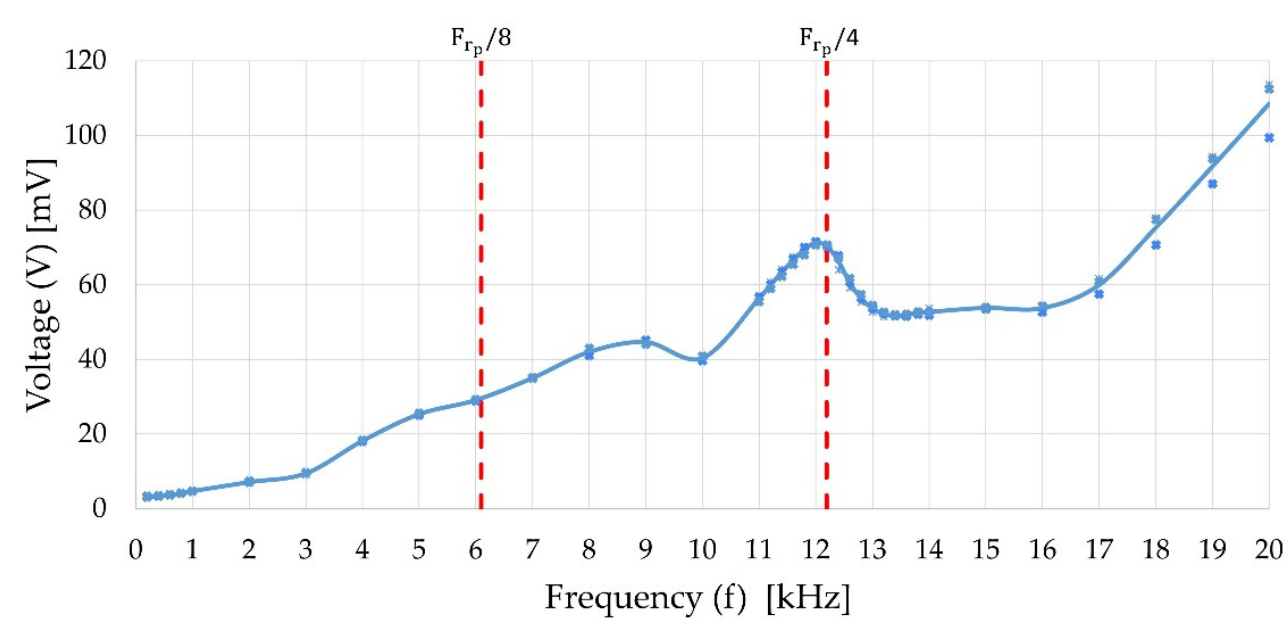

Figure 7. Variations in the open-circuit voltage with the sound frequency where it was found that the voltage increased with the increase in the sound frequency, achieving a peak value at the quarter of the cylinder resonance frequency of $12.2 \mathrm{kHz}$. However, no peak was found at the one-eighth of the resonance frequency.

To investigate this peak, it was necessary to recall the data of the resonance frequencies presented in Table 3, where it can be noticed that this peak frequency represents 0.25025 of the radial resonance frequency $\mathrm{F}_{\mathrm{r}_{\mathrm{p}}}$ where that the radial resonance frequency itself lies outside of the acoustic range.

A possible explanation of this peak was that the sound waves applied from the speakers with a frequency $12.2 \mathrm{kHz}$ would form other overtones with harmonic number, $n$, equals 2-4. Such overtones would be sufficient to create vibrations in the cylinder with its resonance frequency, $\mathrm{F}_{\mathrm{r}_{\mathrm{p}}}$. Moreover, a similar behavior could be expected at the sound frequency $\mathrm{F}_{\mathrm{r}_{\mathrm{p}}} / 8$, where the eighth overtones of such waves could be able to achieve vibrations with the natural frequency. To furtherly investigate this observation, dashed red lines are plotted in Figure 7 at each of the frequencies representing $\mathrm{F}_{\mathrm{r}_{\mathrm{p}}} / 4$ and $\mathrm{F}_{\mathrm{r}_{\mathrm{p}}} / 8$. However, no peak in the voltage was found at the frequency $\mathrm{F}_{\mathrm{r}_{\mathrm{p}}} / 8$. 
In addition to the peak at $\mathrm{F}_{\mathrm{r}_{\mathrm{p}}} / 4$, the voltage tended to increase, starting from the frequency $16 \mathrm{kHz}$ up to the end of the acoustic range. Considering the frequency value $\mathrm{F}_{\mathrm{r}} / 2$ situated at $24.375 \mathrm{kHz}$-outside of the acoustic range, this increase in voltage could be attributed to the left side of a peak that was centered at a frequency of $24.375 \mathrm{kHz}$. Unfortunately, it was not possible to expand this measurement outside of the acoustic range to verify this hypothesis, since the used speakers were rated up to $20 \mathrm{kHz}$ only. Moreover, it would not have been possible to measure the power of the ultrasonic waves to carry out Phase (2).

To investigate the potential relationship between the cylinder size and the frequency of the harvested sound waves, the data presented above were replotted in Figure 8 using a dimensionless frequency, $\mathrm{f}^{\mathrm{O}}$. This dimensionless number was defined to be the ratio between the cylinder diameter and the sound wavelength as shown in Equation (10), where $\mathrm{D}_{\text {cyl }}$ is the outer diameter of the cylinder, $\mathrm{f}$ is the sound frequency, and $\mathrm{U}$ is the sound speed in air taken to be $343 \mathrm{~m} / \mathrm{s}$.

$$
\mathrm{f}^{\mathrm{o}}=\frac{\mathrm{D}_{\text {cyl }}}{\lambda}=\frac{\mathrm{D}_{\text {cyl }}}{\frac{\mathrm{U}}{\mathrm{f}}}=\frac{\mathrm{D}_{\text {cyl }} \mathrm{f}}{\mathrm{U}}
$$

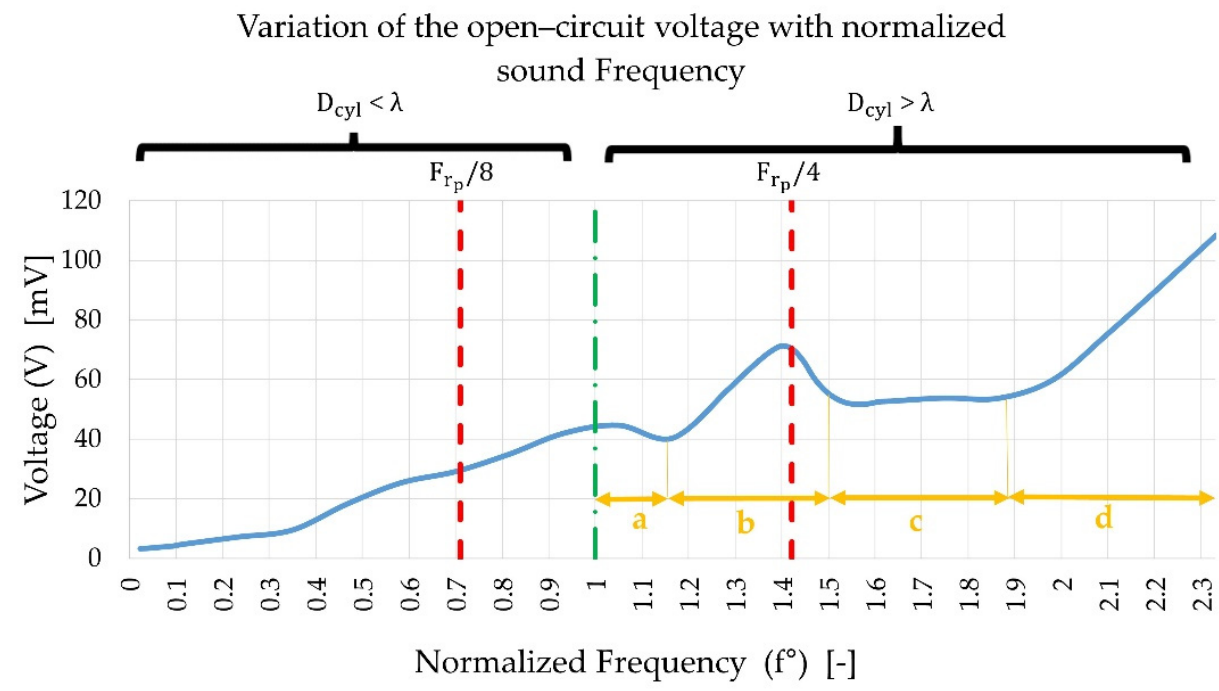

Figure 8. Variations in open-circuit voltage with normalized frequency, $\mathrm{f}^{\mathrm{o}}$, that is defined to be the ratio between the cylinder diameter and the sound wavelength.

By representing the data using the new dimensionless parameter, it was possible to divide Figure 8 into two parts separated by a green separation line at $\mathrm{f}^{\mathrm{o}}=1$. The part on the left of the separation line represents the case when the cylinder diameter was less than the sound wavelength, and the part on the right of the separation line represents the case when the cylinder diameter was greater than the sound wavelength.

It can be noticed that the voltage tended to increase in the left part with increasing frequency up until the separation line exactly. On the other hand, the trend in the right part was different. By examining the right part, one would find that it was composed of four main sections: $a, b, c$, and $d$. Section (a) extended over the range of $\mathrm{f}^{\mathrm{o}}=1-1.16$, where the voltage tended to drop with increasing frequency. Then, Section (b) - the aforementioned peak-extended over the range $\mathrm{f}^{\mathrm{O}}=1.17-1.52$. Then, Section (c) extended over $\mathrm{f}^{\mathrm{O}}=1.52-1.87$, where the voltage was almost constant. Then, Section $(\mathrm{d})$, where the voltage tended to increase with increasing frequency, forming what was thought to be a peak centered at $\mathrm{F}_{\mathrm{r}_{t}} / 2$ outside of the acoustic range.

The difference in the trends of the two halves may be attributed to the relation between the sound wavelength and the cylinder size. In the left half, where the sound wavelength was larger than the cylinder diameter, the sound waves tended to diffract off the cylinder 
without transporting its energy into the cylinder. In other words, the cylinder was not able to well capture the mechanical energy of sound waves of large wavelength and small frequency. As the frequency increased and the wavelength decreased, the sound waves gradually lost their ability to diffract off the cylinder and more energy was transferred from the acoustic waves to the cylinder. This may justify the direct proportionality between the generated voltage and sound frequency in the left half.

When the sound wavelengths reached a critical value that was equal to the cylinder diameter, acoustic waves were no longer able to diffract and were rather either absorbed or reflected off the cylinder. In such a case, energy transfer between the waves and the cylinder depended only on the difference between the acoustic impedance of the two media - the cylinder and the air. Therefore, it would be expected that the right half of the scale would have a constant voltage level which agreed with the obtained data, ignoring Sections (b) and (d), since they are altered by the resonance of the cylinder. However, the drop in voltage in Section (a) remains unjustified.

\subsection{Case (1)}

Figure 9 shows the voltage generated over time in both Cases (1A) and (1B). From Figure 9 , it can be noticed that it took $13 \mathrm{~min}$ to reach the steady-state voltage across the load. Moreover, it was noticed that Case (1A) achieved a high steady-state value of $115.6 \mathrm{mV}$. Unfortunately, it was not possible to measure the flowing electric current. Therefore, the electric power, P, dissipated in the load was determined using Equation (11). Figure 10 shows the power generated in the two cases, where $224 \mu \mathrm{W}$ of power was harvested by the circuit of Case (1A), while only $116 \mu \mathrm{W}$ of power was harvested by the circuit of Case (1B).

$$
\mathrm{P}=\frac{\mathrm{V}^{2}}{\left|\mathrm{Z}_{\mathrm{t}}\right|}=\frac{\mathrm{V}^{2}}{\sqrt{\mathrm{R}^{2}+\left(\mathrm{Z}_{\mathrm{l}}-\mathrm{Z}_{\mathrm{c}}\right)^{2}}}
$$

\section{Comparison between the overall voltage generated from Cases $1 \mathrm{~A}$ and $1 \mathrm{~B}$}

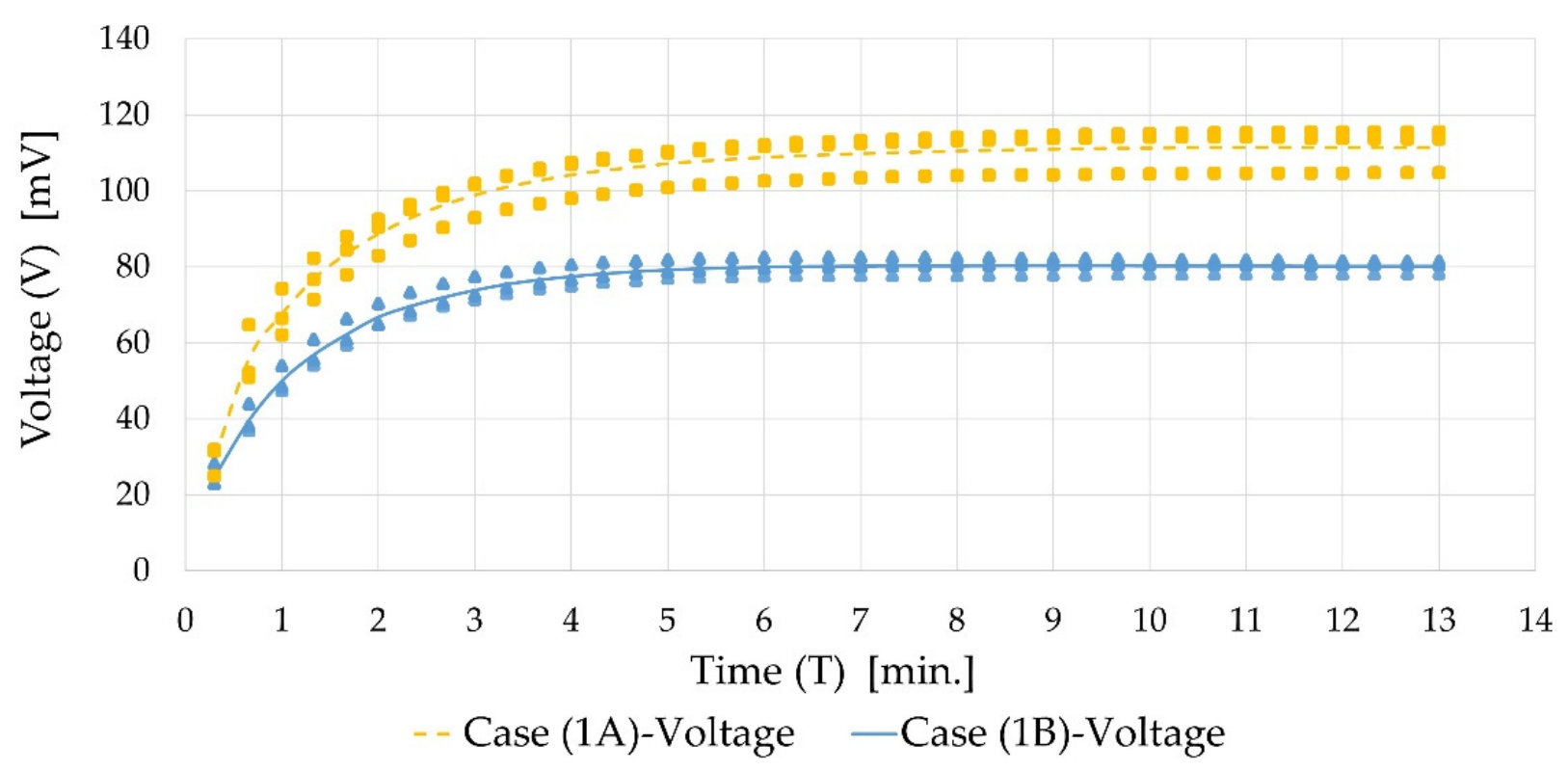

Figure 9. A comparison between the overall voltage generated in Case (1A) and Case (1B), where Case (1A) achieved a higher steady-state voltage. 


\section{Comparison between the power harvested from}

Cases $1 \mathrm{~A}$ and $1 \mathrm{~B}$

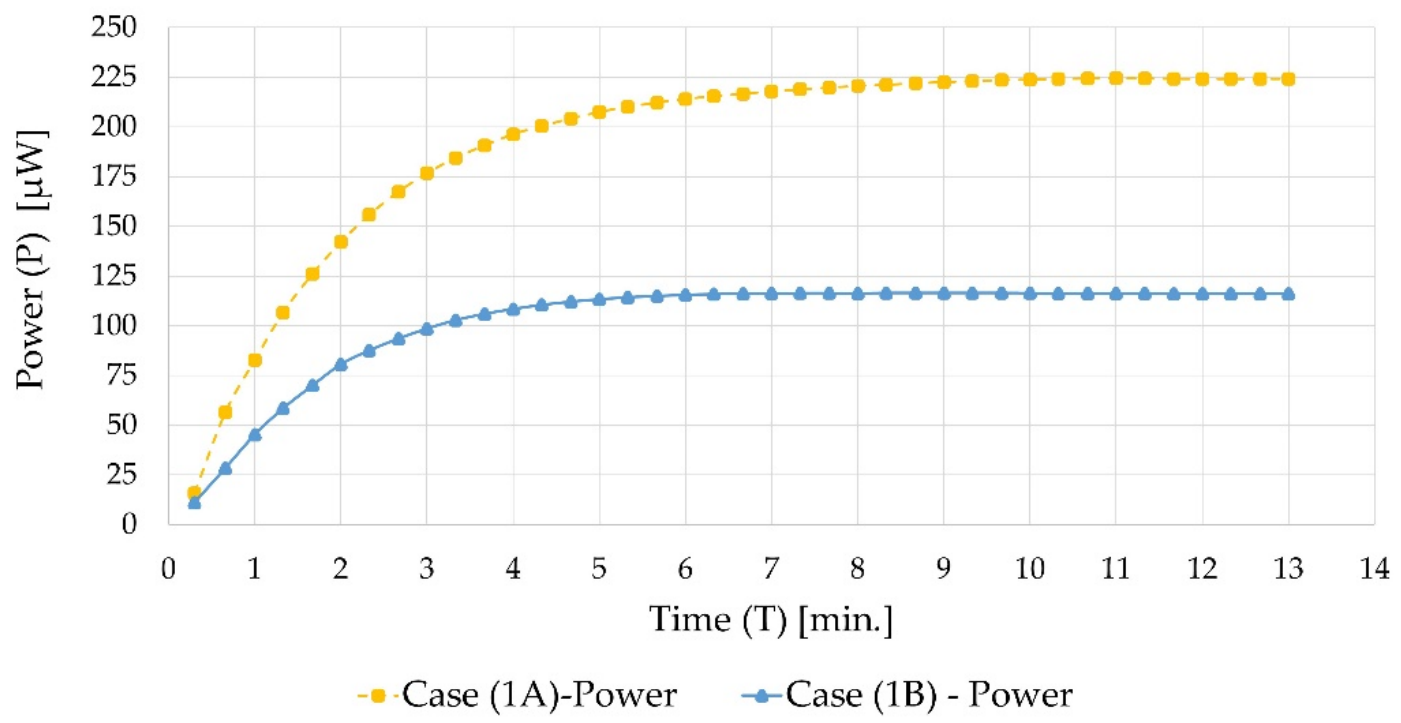

Figure 10. A comparison between the harvested electric power in Case (1A) and Case (1B). Case (1A), using $440 \mu \mathrm{H}$ inductance assuming a signal frequency of $20 \mathrm{kHz}$, achieved a higher power.

\subsection{Case (2)}

3.3.1. Results of Measuring the Electric Power

Figure 11 shows the developed voltage across the load circuit over time in the case of using different capacitors, while Figure 12 shows the dissipated power in the load for each case. It was found that the load circuit with the $10 \mu \mathrm{F}$ capacitor achieved the highest steady-state voltage. However, the circuit with the $1 \mu \mathrm{F}$ capacitor dissipated the most power. This agrees with the data shown in Table 5, where it was expected that the circuit with the $1 \mu \mathrm{F}$ capacitor would dissipate the most power since it had the best impedance match among the three circuits.

Comparison between the overall generated voltage at different

\section{Capacitors}

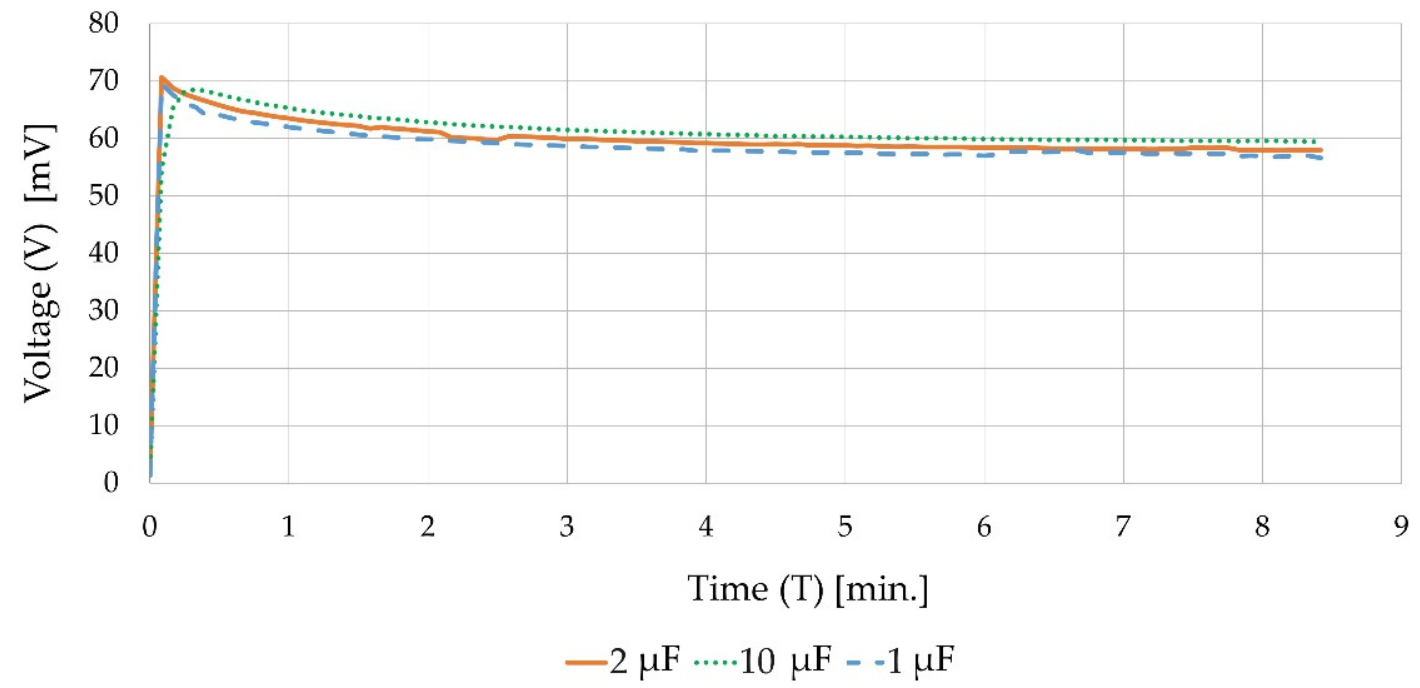

Figure 11. A comparison between the overall generated voltages with different capacitors (Case (2)), where the circuit with capacitor $10 \mu \mathrm{F}$ generated the highest steady-state voltage. 


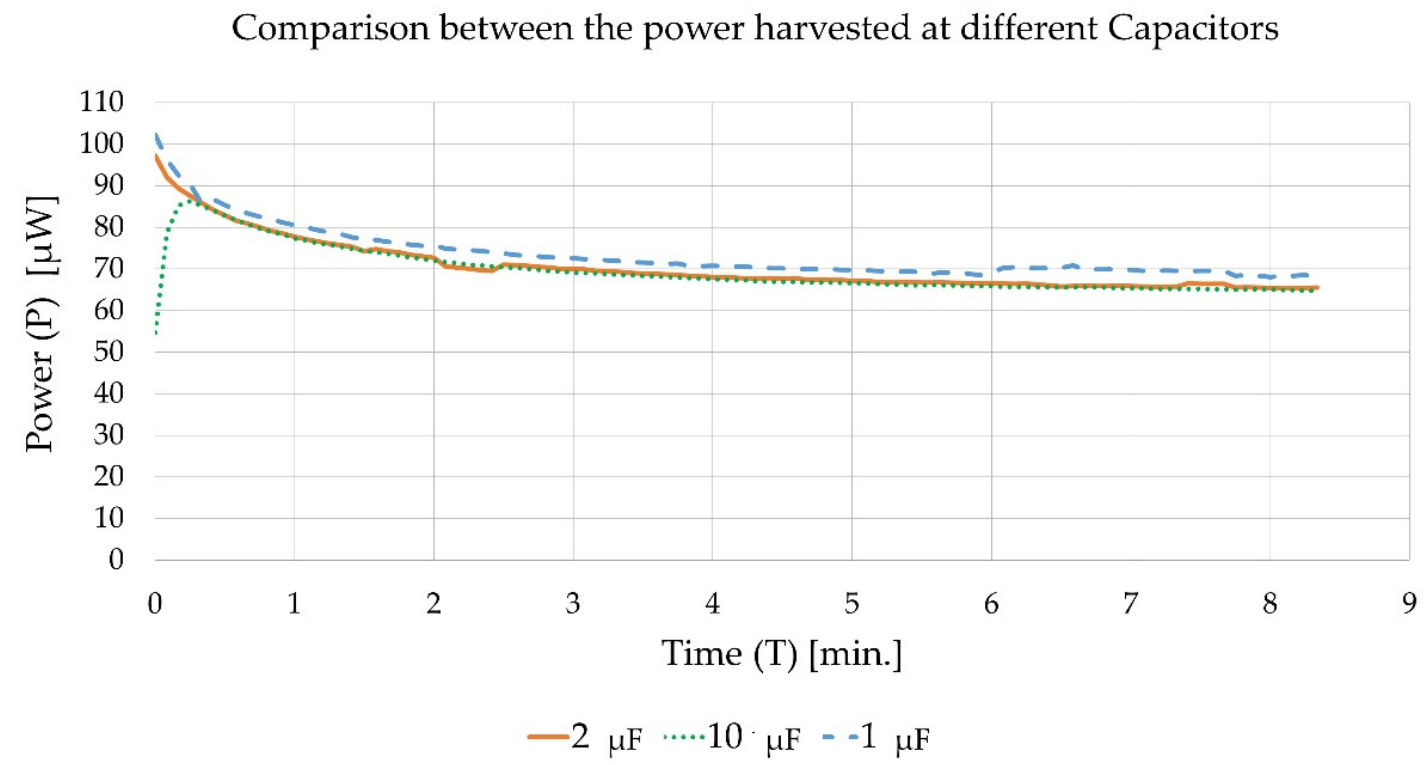

Figure 12. A comparison between the overall dissipated power with different capacitors, where the circuit with capacitor $1 \mu \mathrm{F}$ generated the highest steady-state power.

\subsubsection{Results of Measuring the Acoustic Power}

The mentioned measurement was conducted at several points at different distances from the speakers. For reference, the FFT (fast Fourier transform) of the sound pressure level measured at a distance of three centimeters is shown in Figure 13, while Figure 14 plots the variation in the $20 \mathrm{kHz}$ component with the distance from the source compared to the diameter of the cylinder. From Figure 14, it can be noticed that there were points of local maxima and local minima which is a property of the near-field sound. The highest pressure level, $\mathrm{L}_{\mathrm{p}}$, was achieved at a distance of three centimeters with a value of $102 \mathrm{~dB}$. Using Equations (8) and (9) together with the $L_{p}$ value at a distance of three centimeters, it would be possible to calculate the total acoustic power collected by the cylinder to be $78.5 \mu \mathrm{W}$.

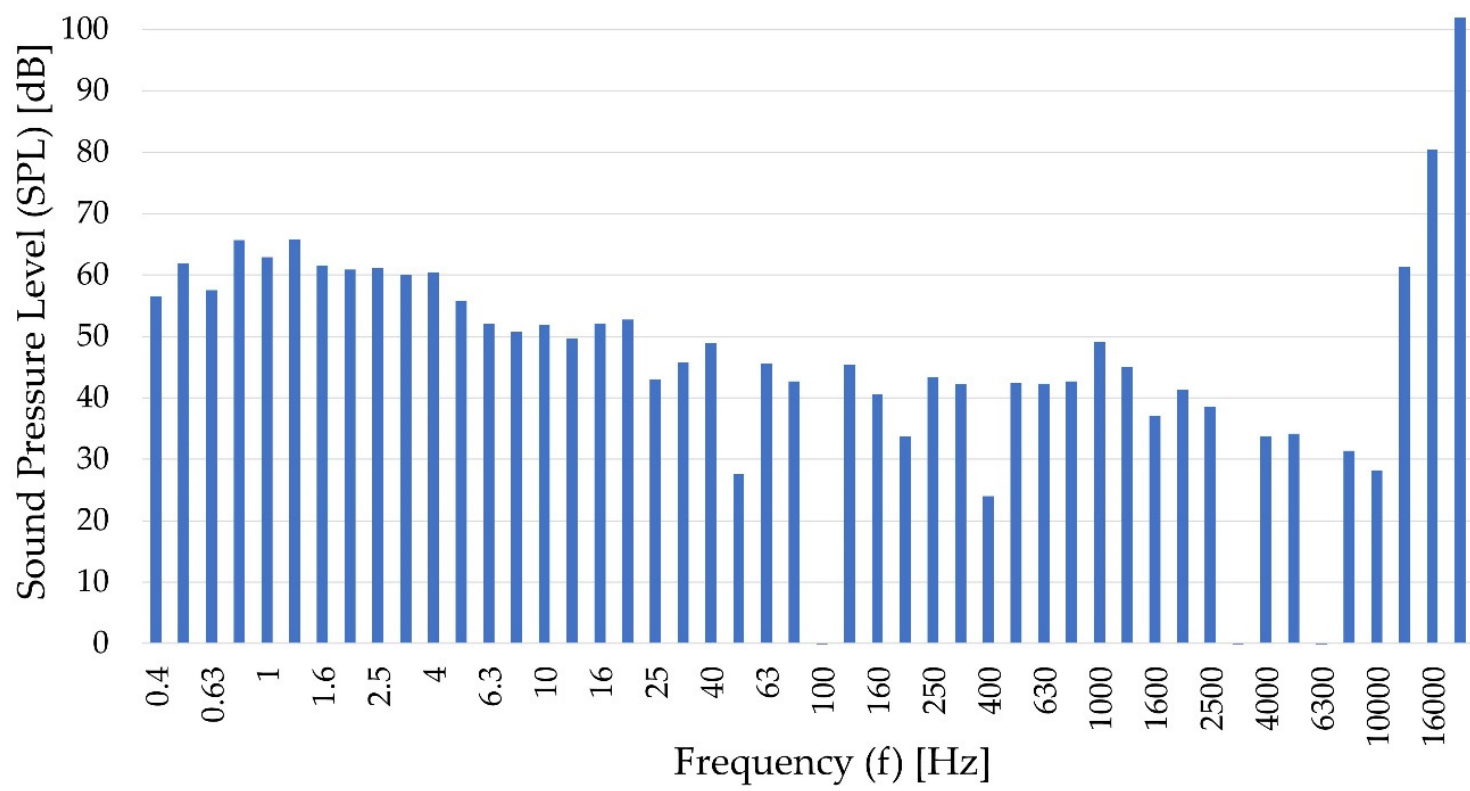

Figure 13. FFT (fast Fourier transform) of the sound pressure level measured at a distance of $3 \mathrm{~cm}$ from the speakers. 


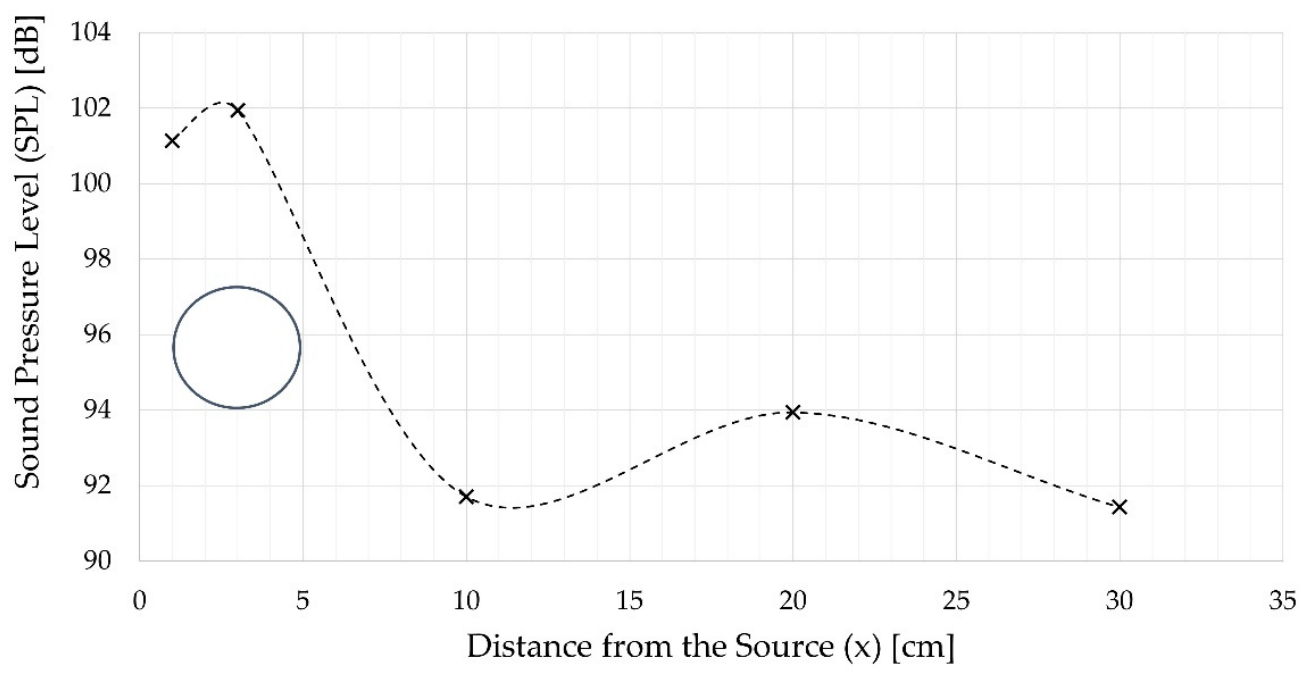

Figure 14. Variations in the sound pressure level with distance away from the source.

\subsubsection{Estimation of the Energy Conversion Efficiency}

To evaluate the performance of the considered energy harvester, it was possible to use Equations (12) and (13) to calculate the harvesting efficiency, $\eta$, and energy harvesting density, $p$, respectively. The results obtained from the data of the three capacitor cases are summarized in Table 6, where it was found that the optimized harvester with the capacitor of $1 \mu \mathrm{F}$ achieved a harvesting efficiency of $86.1 \%$ with an energy-harvesting density of $1.3455 \mu \mathrm{W} / \mathrm{cm}^{2}$ per unit squared centimeter of the cylinder's surface area.

$$
\begin{gathered}
\eta=\frac{P}{P_{\text {acoustic }}} \\
\mathrm{p}=\frac{\mathrm{P}}{\mathrm{A}_{\text {cyl }}}=\frac{\mathrm{P}}{\Pi_{\text {cyl }} \mathrm{L}_{\text {cyl }}}
\end{gathered}
$$

Table 6. Evaluation of energy harvesting using a cylindrical piezoelectric transducer.

\begin{tabular}{cccccc}
\hline $\begin{array}{c}\text { Used Load } \\
\text { Ca-Pacitor, } \mathbf{C}(\mu \mathrm{F})\end{array}$ & $\begin{array}{c}\text { Steady-State } \\
\text { Voltage, V (mV) }\end{array}$ & $\begin{array}{c}\text { Steady-State Power, } \\
\mathbf{P}(\boldsymbol{\mu W})\end{array}$ & $\begin{array}{c}\text { Harvesting Density, } \mathbf{P} \\
\left(\mu \mathbf{W} / \mathbf{c m}^{2}\right)\end{array}$ & $\begin{array}{c}\text { Harvesting } \\
\text { Efficiency, } \boldsymbol{\eta}(-)\end{array}$ & $\begin{array}{c}\text { Voltage Rectification } \\
\text { Efficiency, } \boldsymbol{\eta}_{\mathbf{v}}(-)\end{array}$ \\
\hline 2 & 57.65 & 64.72 & 1.2882 & $82.4 \%$ & $11.77 \%$ \\
\hline 10 & 59.3 & 64.4 & 1.2818 & $82 \%$ & $12.07 \%$ \\
\hline 1 & 56.6 & 67.6 & 1.3455 & $86.1 \%$ & $11.58 \%$ \\
\hline
\end{tabular}

\subsubsection{Estimation of the Effect of the Electric Circuit}

To evaluate the voltage drop imposed by the electric circuit, Equation (14) was devised to calculate the voltage rectification efficiency, $\eta_{v}$, where $V$ is the steady-state voltage across the load, and $V_{\text {loss }}$ is the voltage drop across the bridge. As was mentioned previously in Section 2.3.2, the full-wave rectifier bridge imposed a total voltage drop, $\mathrm{V}_{\text {loss }}$, of $432 \mathrm{mV}$. Therefore, it would be possible to calculate $\eta_{\mathrm{v}}$ for the different load circuits as summarized in Table 6. It is worth mentioning that the voltage rectification efficiency depended mainly on the forward voltage drop of the used diodes and the steady-state voltage generated by the cylinder. The steady-state voltage itself was related to-via the voltage constant of the piezoelectric material-the mechanical pressure applied on the harvester. In applications of acoustic energy harvesting, the magnitude of the pressure of the involved vibrations is 
relatively small. Therefore, the generated steady-state voltage will also be small, lowering the value of the voltage rectification efficiency.

$$
\eta_{\mathrm{v}}=\frac{\mathrm{V}}{\mathrm{V}+\mathrm{V}_{\mathrm{loss}}}
$$

\section{Discussion}

\subsection{Effect of the Size of the Geometry of the Transducer on the Energy Harvesting Process}

Based on the results obtained from the open-circuit measurements performed at different frequencies, it can be concluded that there is a critical sound frequency above which acoustic energy harvesting by a cylindrical transducer is improved. This frequency is related to a property of sound waves which is sound diffraction. Such a property would not be relevant in the case of other geometries such as plate-shaped, ring-shaped or bending element transducers.

This critical frequency was based on the relationship between the corresponding sound wavelength and the diameter of the cylinder. By studying Equation (10), it can be concluded that the bigger the cylinder is, the smaller this critical sound frequency. In other words, the cylinder will have a wider frequency range over which its harvesting performance is improved. Therefore, the next step would be to verify this hypothesis by studying the harvesting performance of cylinders of different diameters. Moreover, it would be interesting to compare the harvesting performance of these cylinders to the performance of a plate-shaped transducer made from the same piezoelectric material.

\subsection{Evaluation of the Complete Energy Harvester}

It has been practically demonstrated that these piezoelectric cylinders can be used to harvest and store acoustic energy at a frequency of $20 \mathrm{kHz}$. The cylinder was able to harvest $67.6 \mu \mathrm{W}$ of acoustic energy with an efficiency of $86.1 \%$ and an energy-harvesting density of $1.3455 \mu \mathrm{W} / \mathrm{cm}^{2}$. In order to compare this piezoelectric cylinder to the other harvesters, the evaluation method set by the authors in [18] was used, where they calculated the Metric parameter defined in Equation (1) for various harvesters reported in the literature. By applying Equation (1) on the piezoelectric cylinder proposed in this paper, it turns out that the piezoelectric cylinder achieved a Metric of 0.2152 which outperformed 16 out of the 17 designs on their list. In the following section, some of the interesting designs that share some of the working conditions of the piezoelectric cylinder are highlighted for a more in-depth comparison. A summary of the data on these harvesters can be found in Table 7.

Table 7. A comparison between the piezoelectric cylinder and other harvesters reported in the literature.

\begin{tabular}{|c|c|c|c|c|c|}
\hline Harvester & Conceptof Transducer & Incident SPL (dB) & $\begin{array}{c}\text { Sound Frequency } \\
\mathbf{k H z}\end{array}$ & $\begin{array}{l}\text { Power Output } \\
(\mu W)\end{array}$ & $\begin{array}{c}\text { Metric } \\
{\left[\mu \mathrm{W} /\left(\mathrm{cm}^{3} \mathrm{~Pa}^{2}\right)\right]}\end{array}$ \\
\hline Piezoelectric cylinder & Piezoelectric & 101 & 20 & 67.6 & 0.2152 \\
\hline [23] & Electro-magnetic & 100 & $\begin{array}{c}0.319 \\
\text { (resonance condition) }\end{array}$ & 789.6 & 14.536 \\
\hline [24] & $\begin{array}{l}\text { Piezoelectric with a } \\
\text { Helm-Holtz resonator }\end{array}$ & 149 & $\begin{array}{c}13.57 \\
\text { (resonance condition) }\end{array}$ & $6 * 10^{-6}$ & $7.7228 * 10^{-12}$ \\
\hline [25] & $\begin{array}{l}\text { Multiple piezoelectric } \\
\text { cantilever plates with a } \\
\text { quarter-wavelength } \\
\text { straight tube resonator }\end{array}$ & 110 & 0.199 & 12,697 & 0.187 \\
\hline
\end{tabular}

The design presented by Khan et al. [23] had a Metric score of $14.536 \mu \mathrm{W} /\left(\mathrm{cm}^{3} . \mathrm{Pa}^{2}\right)$, and it was the only design with a Metric that was higher than that of the piezoelectric cylinder; it is based on electromagnetic transduction rather than piezoelectric. It harvests acoustic energy using a set of composed wound coils mounted on a thin membrane, a permanent magnet, and a Helmholtz resonator. Energy harvesting starts when the 
acoustic waves make the air particles vibrate inside the Helmholtz resonator. Because of the resonation mechanism of the resonator, the vibration of the air particles inside the resonator neck is amplified which, in turn, induces vibrations in the thin membrane causing motion of the coil. Then, the induced motion of the coil relative to the permanent magnet eventually generates electric energy. The design managed to provide a voltage of $198.7 \mathrm{mV}$ over a load of $50 \Omega$. This means it harvested $789.6 \mu \mathrm{W}$ of electric power. The input sound waves were of a frequency of $319 \mathrm{~Hz}$ - the resonance frequency of this harvester-and an SPL of $100 \mathrm{~dB}$, which is quite similar to the SPL used in the experiment performed on the piezoelectric cylinder. By comparing the operating conditions of this harvester to the operating conditions of the piezoelectric cylinder, it can be noticed that the two harvesters shared the same operating sound pressure. However, the electromagnetic harvester was operating at its resonance frequency, while the cylinder was operating at a frequency near to half of its resonance frequency where the resonance frequency lies outside of the acoustic range.

Among the designs in the list in [18] was the harvester proposed by Horowitz et al. in [24]. Their harvester is a micro-machined acoustic energy harvester that uses a Helmholtz resonator to amplify the sound pressure. The harvester uses a silicon wafer as a diaphragm and a ring-shaped PZT as a piezoelectric material. They were able to harvest $6 * 10^{-6} \mu \mathrm{W}$ with the harvester at the resonance frequency of $13.57 \mathrm{kHz}$ from sound waves of SPL of $149 \mathrm{~dB}$. This design had the highest operating sound frequency in the list, where it presented $67.8 \%$ of the sound frequency used by the piezo-cylinder. Yet, the cylinder outperformed this design as can be seen by the Metric number, where this design achieved a Metric of $7.7228 * 10^{-12}$.

Another design that was mentioned in the same comparison was the design reported by Li et al. [25]. This energy harvester is based on a quarter-wavelength straight tube resonator and multiple piezoelectric cantilever plates placed in the first half of the tube. This harvester was able to harvest remarkably high electric power-it was the highest in the list-where it generated $12,697 \mu \mathrm{W}$ of power at an SPL of $110 \mathrm{~dB}$ and a frequency of $199 \mathrm{~Hz}$. This high power was harvested by a relatively compact harvester, where it scored a Metric value of 0.187 . It would be difficult to compare this design to the cylinder, since they were designed for two very different sound frequencies- $199 \mathrm{~Hz}$ versus $20 \mathrm{kHz}$. However, if the cylinder is to be coupled with other harvesters and a resonator, it can have the potential to harvest more energy even at smaller sound frequencies.

\section{Conclusions}

This article examined the potential of acoustic energy harvesting using a cylindrical piezoelectric transducer. It was found that it had better performance at high-frequency sound waves, where it generated a maximum voltage of $112.5 \mathrm{mV}$ at the highest acoustic frequency, $20 \mathrm{kHz}$. Moreover, it is believed that sound diffraction affects the process of energy harvesting, where sound waves that are longer than the cylinder diameter-of a frequency less than $9 \mathrm{kHz}$-diffract off the cylinder minimizing the energy transfer to the cylinder.

Moreover, a complete energy harvester was built from the cylinder. Measurements were performed on several load circuits testing the effect of impedance matching. The efficiency of the energy harvesting process was calculated at a frequency of $20 \mathrm{kHz}$ for the most impedance-matched circuit. It was found that the cylinder generated a steadyvoltage of $56.6 \mathrm{mV}$ with a rectification efficiency of $11.58 \%$. Power-wise, the cylinder harvested of $67.6 \mu \mathrm{W}$ of acoustic power, achieving a harvesting efficiency of $86.1 \%$ and energy-harvesting density of $1.3455 \mu \mathrm{W} / \mathrm{cm}^{2}$ of the cylinder surface area. The results showed that the cylinder outperformed some of the energy harvesters presented in the literature from the point of view of performance in relation to compactness.

Author Contributions: Conceptualization, S.S., K.F., and I.N.; methodology, S.S.; validation, K.F.; formal analysis, S.S.; investigation, S.S.; resources, S.S.; data curation, S.S.; writing-original draft preparation, S.S.; writing-review and editing, S.S. and K.F.; visualization, S.S.; supervision, K.F.; 
project administration, I.N., K.F.; funding acquisition, I.N. All authors have read and agreed to the published version of the manuscript.

Funding: The work was financially supported by the project "Hybrid Materials for Hierarchical Structures", Research Goal: Composite Materials and Structures, Research Program: Materials and Structures on the Metal Basis (reg. no. CZ.02.1.01/0.0/0.0/16_019/0000843) provided by the European Union and the Czech government.

Institutional Review Board Statement: Not applicable.

Informed Consent Statement: Not applicable.

Data Availability Statement: All data are available from the authors on request.

Conflicts of Interest: The authors declare no conflict of interest. Moreover, the funders had no role in the design of the study; in the collection, analyses, or interpretation of data; in the writing of the manuscript, or in the decision to publish the results.

\section{References}

1. Noh, H. Acoustic Energy Harvesting Using Piezoelectric Generator for Railway Environmental Noise. Adv. Mech. Eng. 2018, 10, 1-9. [CrossRef]

2. Ma, Y.; Ji, Q.; Chen, S.; Song, G. An Experimental Study of Ultra-Low Power Wireless Sensor-Based Autonomous Energy Harvesting System. J. Renew. Sustain. Energy 2017, 9, 054702. [CrossRef]

3. Drossel, W.; Kunze, H.; Buchte, A.; Weisheit, L.; Pagel, K. Smart ${ }^{3}$-Smart Materials for Smart Applications. Proc. CIRP 2015, 36, 211-216. [CrossRef]

4. Kim, H.S.; Kim, J.; Kim, J. A Review of Piezoelectric Energy Harvesting Based on Vibration. Int. J. Precis. Eng. Manuf. 2011, 12, 1129-1141. [CrossRef]

5. Ramar, M.; Balasubramanian, S. Development of Piezoelectric Property Materials for the Nanogenerator Production. Res. J. Chem. Environ. Sci. 2018, 6, 114-123.

6. Dahiya, R.S.; Valle, M. Robotic Tactile Sensing, 1st ed.; Springer: The Netherlands, 2013. [CrossRef]

7. Butt, Z.; Pasha, R.A. Effect of Temperature and Loading on Output Voltage of lead zirconate titanate (PZT-5A) Piezoelectric Energy Harvester. IOP Conf. Ser. Mater. Sci. Eng. 2016, 146, 012016. [CrossRef]

8. Salem, S.; Fraňa, K.; Nová, I. Design of Acoustic Energy Harvesting Unit Using Piezo-Electric Diaphragm. Mater. Sci. Forum 2019, 986, 109-115. [CrossRef]

9. Fleming, A.J.; Moheimani, S.O.R. Fundamentals of Piezoelectricity. In Piezoelectric Transducers for Vibration Control and Damping; Springer: London, UK, 2006. [CrossRef]

10. Saadon, S.; Sidek, O. A Review of Vibration-Based MEMS Piezoelectric Energy Harvesters. Energy Convers. Manag. 2011, 52, 500-504. [CrossRef]

11. Hassan, H.F.; Idris, S.; Hassan, S.; Rahim, R.A. Acoustic Energy Harvesting Using Piezoelectric Generator for Low Frequency Sound Waves Energy Conversion. Int. J. Eng. Technol. 2013, 5, 4702-4707.

12. Nakamura, H. Vortex Shedding Suppression for a Circular Cylinder by Attaching Cylindrical Rings (A Consideration of the Mechanism). In Proceedings of the ASME-JSME-KSME Joint Fluids Engineering Conference, Shizouka, Japan, $24-27$ July 2011.

13. Gao, X.; Shih, W.; Shih, W.Y. Flow Energy Harvesting Using Piezoelectric Cantilevers with Cylindrical Extension. IEEE Trans. Ind. Electron. 2013, 60, 116-118. [CrossRef]

14. Yang, Z.; Erturk, A.; Zu, J. On the Efficiency of Piezoelectric Energy Harvesters. Extrem. Mech. Lett. 2017, 15, 26-37. [CrossRef]

15. Richards, C.D.; Anderson, M.J.; Bahr, D.F.; Richards, R.F. Efficiency of Energy Conversion for Devices Containing a Piezoelectric Component. J. Micromech. Microeng. 2004, 14, 717-721. [CrossRef]

16. Shu, Y.C.; Lien, I.C. Analysis of Power Output for Piezoelectric Energy Harvesting Systems. Smart Mater. Struct. 2006, 15, 1499-1512. [CrossRef]

17. Liao, Y.; Behrend, P.S.; Sodano, H. Structural Effects and Energy Conversion Efficiency of Power Harvesting. J. Intell. Mater. Syst. Struct. 2009, 20, 505-514. [CrossRef]

18. Yuan, M.; Cao, Z.; Luo, J.; Chou, X. Recent Developments of Acoustic Energy Harvesting: A Review. Micromachines 2019, 10, 48. [CrossRef]

19. Monroe, N.M.; Lang, J.H. Broadband, large scale acoustic energy harvesting via synthesized electrical Load: Harvester design and model. Smart Mater. Struct. 2019, 28, 055032. [CrossRef]

20. Fletcher, M.D.; Lloyd Jones, S.; White, P.R.; Dolder, C.N.; Lineton, B.; Leighton, T.G. Public Exposure to Ultrasound and Very High-Frequency Sound in Air. J. Acoust. Soc. Am. 2018, 144, 2554-2564. [CrossRef] [PubMed]

21. Muthalif, A.G.A.; Nordin, N.H.D. Optimal Piezoelectric Beam Shape for Single and Broadband Vibration Energy Harvesting: Modeling, Simulation and Experimental Results. Mech. Syst. Signal Process. 2015, 54-55, 417-426. [CrossRef] 
22. Salem, S.; Fraňa, K.; Nová, I.; Erhart, J. Acoustic Energy Harvesting Using Piezo-Electric Materials. In Proceedings of the 2020 International Youth Conference on Radio Electronics, Electrical and Power Engineering (REEPE), Moscow, Russia, 12-14 March 2020; pp. 1-6. [CrossRef]

23. Khan, F.; Izhar. Electromagnetic Energy Harvester for Harvesting Acoustic Energy. Sādhanā 2016, 41, 397-405. [CrossRef]

24. Horowitz, S.B.; Sheplak, M.; Cattafesta, L.; Nishida, T. MEMS Acoustic Energy Harvester. J. Micromech. Microeng. 2006, 16, 12-16. [CrossRef]

25. Li, B.; You, J.H.; Kim, Y.J. Low Frequency Acoustic Energy Harvesting Using PZT Piezoelectric Plates in a Straight Tube Resonator. Smart Mater. Struct. 2013, 22, 055013. [CrossRef] 